\title{
Ways of Interacting: What Underlies Instructional Coaches' Discursive Actions
}

Mari Haneda, Brandon Sherman, Frances Nebus Bose, Annela Teemant

\section{Introduction}

Instructional coaching has become a widely practiced form of professional development in schools. Most of the published research has examined topics such as effective strategies used by coaches (Walpole \& Blamey, 2008), the roles that coaches play in schools (Bean, Draper, Hall, Vandermolen, \& Zigmond, 2010), and the statistically measured impact of coaching on teacher classroom practices and student academic performance (e.g., Kraft, Blazar, \& Hogan, 2018; Neuman \& Wright, 2010). Recently, new research on the dynamics of teacher-coach conference interaction has emerged, revealing that coaches use a continuum of stances from directive to facilitative (e.g., Collet, 2012; Heineke, 2013). However valuable identifying the distribution of coach stances in moment-by-moment interactions is, we argue that it is equally important to attend to coaches' overall or macro-orientations when coaching, which we define as their underlying values and assumptions about teaching and learning. We address this issue through a single case study (Merriam \& Tisdell, 2016) of a respected and experienced instructional coach, Sabrina. We explore how her characteristic ways of guiding in-service teachers in coach-teacher conferences reveal her underlying assumptions about teaching and learning. We compare her discursive choices with those made by Gina, a district coach in training, when the latter interacted with the same first-grade teacher. Our aim is not to produce "statistically-based" generalizations, but rather an "analytic generalization" (Yin, 2003, pp. 31-33) as the basis for the development of a theory of coach-teacher interaction in effective coaching.

\section{Review of Relevant Research}


In this section, we briefly review previous research on coach-teacher interaction to situate our study in relation to this literature. We then provide a description of the critical sociocultural theoretical perspectives on which the Six Standards Pedagogy and Instructional Coaching are based (Author, 2018; Authors, 2014).

\subsection{Research on Coach-Teacher Interaction}

There is considerable variation in the arguments put forward with respect to the models and purposes of coaching as a professional development strategy (e.g., International Literacy Association, 2018; Knight, 2009). Prominent examples include discipline specific coaching (e.g., Toll, 2014), cognitive coaching (Costa, Garmston, Hayes, \& Ellison, 2016), and instructional coaching (Knight, 2007). By definition, coaches are assumed to be dedicated specialists tasked with the professional development of the inservice teachers with whom they work. This distinguishes instructional coaching from peer coaching between in-service teachers (Charteris \& Smardon, 2014; Murray, Ma, \& Mazur, 2009), mentoring of pre-service teachers by cooperating teachers (Hoffman et al., 2015; Maloch et al., 2015), and other forms of teacher mentoring (Crasborn, Hennissen, Brouwer, Korthagen, \& Bergen, 2011).

A large body of research has found that effective coaching requires good interpersonal relations between coaches and teachers, created through establishing rapport, mutual respect, and reciprocal trust (e.g., Borman \& Feger, 2006; Obara, 2010). Thus, coach-teacher interaction in conferences has become an important area of research. Some studies on coach-teacher interaction have focused on the negotiation of identity (Rainville \& Jones, 2008, Skinner, Hagood, \& Provost, 2014), emotions (Hunt, 2016), and Discourse (Hunt, 2018). However, the majority have focused on the ways coaches position themselves in relation to teachers in coach-teacher interaction; by 
examining the discursive moves used by coaches, researchers have identified different coaching stances in moment-by-moment interaction, characterized by the coach's choice of interactional strategy and the tenor of the interaction (e.g. Collet, 2012; Deussen, Coskie, Robinson, \& Autio, 2007; Heineke, 2013; Ippolito, 2010). Coaching stances in moment-by-moment interaction are characterized broadly as directive or responsive (or reflective). A coach adopting a directive stance acts in the role of expert and/or authority, providing direction and advice in a mainly prescriptive manner. On the other hand, a coach taking a responsive stance acts in a manner designed to elicit reflection on the part of the teacher.

Some researchers have posited that these directive and responsive stances are distinct coaching positions (Deussen et al., 2007; Dozier, 2006), whereas others have noted that coaches must be able to make use of both stances in different circumstances in order to adapt to the changing needs of individual teachers in moment-by-moment interaction (Collet, 2012; Ippolito, 2010). Prior studies have revealed the distributional patterns of coaches' use of particular discursive moves and explored, to some extent, the contexts in which they might employ one stance or another. However, left unexamined is an exploration of discursive moves in terms of coaches' macro-interactional orientations. ${ }^{1}$ If the use of coaching stance (directive/responsive) is to be understood as a coach's strategic decision in an interactional situation, the question of how coaches orient themselves across situations remains open for investigation. In this paper, we examine how coaches' values and assumptions about the nature of learning - what we

\footnotetext{
${ }^{1}$ Some studies (e.g., Rainville \& Jones, 2008; Skinner, Hagood, \& Provost, 2014; Hunt, 2014 \& 2018) did address macro issues, broadly conceptualized, such as emotions and identity as realized in coach-teacher interaction. However, our focus is distinctly different; it focuses on macro-interactional orientations that underscore decision-making across interactional events.
} 
describe as their macro-interactional orientation — might relate to the decisions they make regarding the stances they adopt across different coaching situations.

\subsection{Critical Sociocultural Perspectives on Education}

The Six Standards Pedagogy (Authors, 2014) ${ }^{2}$, the basis of the coaching approach examined here, is informed by critical sociocultural theory (e.g., Gutiérrez \& Vossoughi, 2010; Lewis, Enciso, \& Moje, 2007; Vossoughi, \& Gutiérrez, 2016). It draws on Vygotsky's (1978) sociocultural theory, and it is also inspired by the work of Freire and other critical theorists (Freire, 1970/2002; Kincheloe, McLaren, \& Steinberg, 2011).

Two important features of sociocultural theory, on which Six Standards Pedagogy builds, are, first, that all human psychological processes grow out of collaborative forms of social interaction; and, second, that individual development occurs through the process of entering into a culture by participating in its activities with more experienced members. In this way, individuals gradually appropriate the culture's tools, both material and psychological, as well as the modes of action and thinking that they make possible.

Initially, it is parents and other caregivers who mediate and assist children's learning and development; later, when children start school, the responsibility comes to include teachers, who are professionally prepared for the task. However, while they must plan lessons for the class as a whole, they also have the challenging task of simultaneously providing instruction appropriately pitched in individual students' zones of proximal development (ZPDs) (Vygotsky, 1978).

\footnotetext{
${ }^{2}$ Its official name is the Six Standards for Effective Pedagogy.
} 
The emphasis on critical theoretical perspective brings equity to the forefront, allowing contemporary issues, such as the increasingly linguistic and cultural diversity of the student population, to be addressed as recently arrived immigrant students learn subject matter in a new language. When facing such student diversity, it is particularly important that teachers engage students in dialogue, respecting them as partners who contribute to learning by drawing on their varied experiences and capabilities. This dialogue creates spaces in which teachers help students see the world "not as a static reality, but as a reality in process, in transformation" (Freire, 1970/2002, p. 4). This idea of dialogic engagement - or interaction- is equally applicable to the coach-teacher relationship, as this allows space to question the taken-for-granted routines and experiment with new ideas.

Dialogic engagement, according to Freire (1970/2002), is a dialogue between the Self and the Other - a dialectic of mutual becoming. While also adopting this premise, Bakhtin (1986, p. 143) considered this dialectic to be more precarious, provisional, and involving constant tension: “All of each individual's words are divided into the categories of his own and others', but the boundaries between them can change, and a tense dialogic struggle takes place on the boundaries." Thus, while dialogic engagement entails developing intersubjectivity and mutual understanding, it also involves (a) identifying and exploring open questions or points of contention and (b) starting from differences, as these potentially provide opportunities for creating either new understanding or further inquiry through critical discussion (see Gadamer, 1998).

In the next section, we describe how critical sociocultural perspectives on education, organized as six pedagogical guiding principles, inform Six Standards Pedagogy and Instructional Coaching 


\section{Six Standards Pedagogy and Instructional Coaching}

The Six Standards Pedagogy is a program of professional development (PD) based on critical sociocultural perspectives on education as described in the previous section. This PD builds on Tharp and his colleagues' work on linguistically and culturally responsive pedagogy (e.g., Tharp \& Gallimore, 1988). Based on their work in Hawaii and California, Tharp, Estrada, Dalton, and Yamauchi (2000) proposed Five Standards ${ }^{3}$ - five key pedagogical principles - that form the sociocultural theoretical foundation of this pedagogy, which can be appropriately used in any content area.

In what follows, we provide a brief description of each of the five pedagogical principles. The first principle, Joint Productive Activity, refers to teacher and students co-constructing knowledge and generating a shared learning product. It encourages student-student and teacher-students collaboration. The second principle, Language and Literacy Development, calls for structured opportunities - more than 10 minutes in length — for students to engage in sustained reading, writing, or speaking activities with teacher assistance. The third principle, Contextualization, involves teachers' using students' existing knowledge and experiences from home, school, and community as a starting point for new learning. The fourth principle, Challenging Activities, concerns teachers intentionally creating activities that help students to develop higher order thinking while providing timely assistance and feedback. The fifth principle, Instructional Conversation, refers to a goal-directed small-group discussion about an academic concept (e.g., addition or refraction), which is led by the teacher in interaction with a small group of students. This kind of discussion allows the teacher to tailor her or

\footnotetext{
${ }^{3}$ While working with Tharp as a postdoctoral researcher, the first author had a conversation with him about what he meant by "Standards." Tharp explained that the term, standard, refers to a pedagogical principle that, as a heuristic tool, leads and guides teaching practices.
} 
his instruction to the ZPDs of the individual students through the provision of timely assistance (e.g., questioning, rephrasing, modelling). For the Six Standards PD program, a further principle, Critical Stance (CS) (Authors, 2014), was added in order to explicitly include 'critical' dialogic engagement, as this was described in the previous section. CS is also based on the Freirean idea of designing learning experiences that intentionally challenge taken-for-granted norms from multiple perspectives with the aim of teacher and students' engaging in transformative practices, addressing social inequities within students' lives in and outside the classroom (See Author, 2018 for more details). Importantly, these six principles are intended to be enacted in concert with each other, not in isolation.

Six Standards Instructional Coaching, which is theoretically aligned with Six Standards Pedagogy, aims to help teachers to understand, appropriate, and enact this pedagogy. Working one-on-one as dialogic partners, coaches help teachers to articulate their own pedagogical goals and support them in achieving these goals in relation to their students, the curriculum, and the wider institutional context. Thus, the coaching aims to achieve two main objectives: (a) to help teachers make sense of and appropriate the Six Standards pedagogical principles and the theoretical ideas underpinning them; and (b) to help them translate these principles into concrete pedagogical actions that are appropriate for their individual instructional contexts.

\section{Method}

\subsection{Study}

The research question that guided our study was: What characterized the ways in which an experienced coach interacted with a classroom teacher in coach-teacher conferences, as compared with the ways in which a district coach interacted with the 
same teacher? The data on which we draw are taken from one year-long enactment of the Six Standards Pedagogy and Instructional Coaching described above. We conducted a single case study of Sabrina, a Six Standards "expert instructional coach" (Creasy \& Paterson, 2006, p. 18). ${ }^{4}$ To make Sabrina's characteristic ways of interacting salient, we compared her interactions with those of a novice Six Standards coach, Gina, when each of them interacted with the same teacher, Ellie. Throughout the year Gina coached Ellie. While Gina was coaching Ellie, Sabrina took a participant-observer role in Gina's coaching sessions with Ellie, occasionally intervening to model what she considered to be effective coaching. We reasoned that such a comparison might reveal the experienced coach's expertise in practice. Because of this focus, we did not directly address Sabrina's parallel coaching of Gina in this paper.

\subsection{The Larger Context of the Investigation}

Greenfield, the school district in which Gina worked as a coach, is located in a suburb of a metropolis in the Midwest of the USA. In the recent past, the district had experienced a rapid increase in the number of English-as-additional-language students and, in order to proyide more effective instruction for them, they had requested Six Standards Pedagogy to provide professional development for the district's elementary school teachers and for the instructional coaches who were working with them. The district instructional coaches employed by the school district attended an initial coaching workshop and then, for a number of years, were shadowed and assisted by Sabrina, as they worked with classroom teachers who were learning to incorporate the six pedagogical principles into their teaching. All the classroom teachers who

\footnotetext{
${ }^{4}$ Our judgment that Sabrina was effective as an instructional coach was supported by the evidence of statistically significant academic gains made by students who were taught by teachers whom Sabrina had coached (Author et al., 2014; Authors., 2017).
} 
participated in the PD first attended a one-time summer workshop and then received seven cycles of individualized coaching spread over one school year. As part of her coaching, Sabrina sat in on the session in which coaches in training were coaching teachers.

\subsection{The Participants}

In terms of their experience, the three educators involved in our study were at different stages in their careers. Sabrina, the expert coach, had started her career as a bilingual elementary teacher with certification in Reading Recovery and then obtained National Board Certification as an early childhood generalist. She subsequently studied to obtain an Ed.D. degree in Reading. Following graduation, she began to act as a Six Standards instructional coach. Since then, she had been an instructional coach over 10 years in K-12 settings for various grant-funded PD projects in several states within the USA, including Arkansas, California, Indiana, and Massachusetts, as well as overseas, particularly Greenland. More recently, in addition to coaching in-service teachers, she had become the trainer of district coaches involved in the PD program. Thus, her range of experience as a teacher educator was distinctly different from that of typical district coaches, whose careers usually progress from classroom teaching to becoming instructional coaches in the same school district.

Gina was an elementary school teacher with a B.Ed. After several years of classroom teaching in the district, she was judged to be an exemplary teacher and was recruited to become a coach in the same district. At the time we observed her, she was in her third year of preparation as a Six Standards coach under Sabrina's guidance. During that year, Sabrina observed Gina's interactions with the teachers she coached 
and was present during the related classroom observations; she also held a debriefing session with Gina at the end of each coaching cycle.

Ellie was a relatively novice first-grade teacher and, in her second year of the Six Standards PD program, was being coached by Gina. However, it was the first year in which Ellie and Gina were working together. Over the course of the school year, each time that Gina coached Ellie, Sabrina sat in on the session. For most of the time during these sessions Sabrina simply observed, contributing only when requested to do so by either Gina or Ellie. However, she did occasionally intervene on her own initiative.

\subsection{Data Sources and Analytical Procedures}

The primary data we used for the current analysis were video-recordings of coach-teacher interactions in pre- and post-observation conferences. ${ }^{5}$ We also used two types of interview data. The first consisted of two semi-structured face-to-face interviews with Ellie, namely an intake interview conducted by the coach and an exit interview conducted by the PD development team, about the quality of the coaching experience at the end of the PD. The second took the form of video-cued interviews with each of the three participants after the PD (to be explained later). Other data sources consulted included Sabrina's observational notes, transcripts of one Instructional Conversation that Ellie conducted, and Gina's written reflections on her coaching practices and Sabrina's responses to them. The analysis was carried out when all the relevant data for the whole year had been collected.

Our analysis involved a series of stages. First, we repeatedly viewed all videorecorded coaching sessions independently, wrote analytical notes on our impressions of what characterized the two coaches' approaches to the coaching process, and then

\footnotetext{
${ }^{5}$ Sabrina made all the video-recordings of coach-teacher conference interactions.
} 
discussed our preliminary interpretations. At each stage, if there were any discrepancies in the way in which the different members of the research team interpreted the data, we discussed them until consensus was reached. Second, using Studiocode (video-analysis software), we collaboratively identified 'episodes' which were defined as relatively selfcontained stretches of talk (e.g., the coach and the teacher negotiating the goal of a coaching session). Each episode of talk consists of one or more sequences, with sequence defined as all the moves required to fulfil the expectations set up by the initiating move around which the sequence is organized (Wells \& Arauz, 2006). Third, we independently identified key episodes that we considered to represent larger patterns that characterized each coach's coaching strategies; any disagreement was discussed until it was resolved. Fourth, we fully transcribed these key episodes and analyzed each of them, using two discourse analysis methods in conjunction: (a) educational discourse analysis informed by sociocultural theory (e.g., Mercer, 2004; Wells \& Arauz, 2006) to identify language functions of each move (e.g., requesting clarification or elaboration, asking for justification) and (b) micro-ethnographic discourse analysis (Bloome, Carter, Christian, Otto, \& Shuart-Faris, 2005 ) to attend to paralinguistic features of utterances so as to interpret utterances in a situated manner. Then, based on these analyses, we wrote extensive analytical notes about each episode.

Finally, in order to confirm our interpretations, we conducted a member-check by means of video-cued interviews with Ellie, Gina, and Sabrina, three years after the completion of the year of instructional coaching. We selected a number of short videoclips, which we considered likely to be thought-provoking moments for the participants. Then, using them as prompts, we conducted interviews using Zoom (web-based videoconferencing platform). The recorded interviews were transcribed and analyzed and then incorporated into our final analysis. We created a narrative account for each coach 
by identifying interactional characteristics from our discourse analytic work and crossreferencing these with the interview data. On this basis, we created the comparative narrative account which follows. The stories we tell are our interpretations of Gina and Sabrina's lived experiences as captured in the video-recordings and the interviews and as revealed through our analysis and interpretation.

\section{Findings}

On the basis of the above analyses, we identified three characteristic ways in which Sabrina fundamentally differed from Gina. First, when coaching, Sabrina's discursive assistance was geared towards helping Ellie articulate her pedagogical goals for the academic year as well as for each classroom activity; by contrast, Gina's assistance focused chiefly on practical matters of implementation. Second, Sabrina adopted a longer time-scale than Gina when commenting on Ellie's development as a teacher. Third, Sabrina encouraged Ellie to think about the perspectives of her students, both as individuals and as a class, whereas Gina tended to refer to Ellie's students collectively as a homogenous group to be managed. In the following sections, we will discuss each of these differences in turn.

\subsection{Reflection versus Action}

We focus on the first of the three differences: Sabrina's orientation to reflection compared with Gina's to action. In supporting Ellie, Sabrina tended to prompt her to articulate the purpose of an activity or what she perceived to be a problematic pedagogical situation, whereas Gina tended to focus primarily on practical issues/matters. For example, when Ellie complained about her children's misbehaviors, the two coaches' responses were strikingly different. Gina interpreted the situation as a 
classroom-management issue and offered Ellie some concrete crowd-control strategies.

By contrast, Sabrina did not offer an immediate solution but, instead, encouraged Ellie to re-assess the situation from her students' viewpoint: "Why do you think the kids were acting up?" Taken by surprise, Ellie, with some hesitation, attributed the problem to her students' boredom. Sabrina pressed on, asking "why?" Ellie responded that her students were disengaged because the activity was not challenging them intellectually. In this way, by asking exploratory questions, Sabrina pushed Ellie to consider the students' perspectives while simultaneously encouraging her to become an agentive professional.

Our analyses also showed that, while Gina did, in fact, ask Ellie many openended questions, the focus of her questions was predominantly on helping Ellie effectively complete her forthcoming activities. For example, when talking about learning centers, Gina asked her: "How can you... help them (students) stay focused? Is it that we need to shorten the time that they're actually doing centers?" Typically, as in this case, it was Gina who identified implementation issues while inviting Ellie to costrategize solutions. The following excerpt is one such example. Here, Gina helps Ellie plan a 'compare-and-contrast' Instructional-Conversation (IC) activity, drawing on multiple versions of the story "The Little Red Hen":

\section{Excerpt $1^{6}$}

G: So, really... if you could do some pre-planning, what would be a couple questions to ask them [students in Ellie's IC group] to push.... You've already read both versions of the story, right?

E: Yes.

\footnotetext{
${ }^{6}$ Contextual glosses are inserted in square brackets.
} 
G: So then... [at the end the class] what are they [students] going to be left to do?

E: Fill in the Venn Diagram.

G: So, continue filling in [the Venn Diagram] ok, so you can model for them like characters, model for them setting [what should go into the Venn Diagrams] and maybe they [students] can do the illustrations.

In this excerpt, taking the lead, Gina walked Ellie through steps of implementation for the activity. Gina focused on actions for Ellie to undertake, such as asking questions, reading the story, completing a Venn Diagram, modelling the setting and characters, and having students complete illustrations. It was not Ellie but Gina who identified the goal and steps that Ellie should take in order for the activity to be successful. By contrast, when Sabrina addressed a similar issue, she first invited Ellie to propose solutions of her own. Furthermore, although Gina directed Ellie to use conceptually focused strategies, such as questions to challenge students' thinking, she herself missed an opportunity to use and model such strategies in her interaction with Ellie.

Another example occurred when Ellie and Gina discussed activities that could be implemented in a listening center. Sabrina intervened, challenging Ellie to ask herself "Why am I doing this?" When Ellie replied, "Cause we've always done it," Sabrina explained that each activity should be connected to Ellie's larger pedagogical goals: "Anything that's going to get in your way (of reaching your longer-term pedagogical goals), then don't put it into your rotation (of learning centers)... We have to ask, "Why am I doing this activity?"

As noted earlier, while Gina and Sabrina used both directive and reflective discursive moves, Sabrina tended to lean towards the reflective while Gina towards the 
directive. However, what fundamentally distinguished the two was the purposes for which their questions were asked, with Gina often asking "what" and "how," and Sabrina asking “why.” In the conferences, Ellie generally resisted Sabrina's requests to reflect on the reasons for her practices.

During a video-cued interview with Ellie three years later, she expressed her appreciation of Gina's practical pedagogical assistance and of how, on some occasions, she encouraged her to come up with her own solutions. Significantly, however, while acknowledging Gina's contributions to her growth as a teacher, she stated that it was Sabrina's coaching that had most influenced how she currently approached teaching; in Ellie's words, Sabrina "made me think.” Ellie attributed this to Sabrina's persistent questioning:

I don't know a nicer way to say but she was gonna push you to think, you know, or get it out I guess... she would question enough that you're gonna figure it out. You're gonna figure out if it's you or this activity or, you know? She knew how to question.

Ellie also explained that it was not until she learned to slow down to give herself time to reflect on what might be causing her children's unruly behavior that she came to "realize that it is not them [children], it is you" that was the problem. By slowing down and giving herself time for reflection, Ellie stated that, over time, reflection had become an important part of her teaching: "I question the kids a lot more... like 'Why do you think that?' or 'Tell me more about that.' Kind of like what Sabrina did to me." At this stage in Ellie's teaching career, it was significant that it was Sabrina's repeated requests to articulate her pedagogical goals for students' learning that seemed to have had a lasting impact on Ellie's development as a teacher. 


\subsection{Short-Term vs. Long-Term Attitudes Toward Teacher Development}

The second difference that emerged from the comparative analysis concerns the two coaches' attitudes towards teacher development. In contrast to Gina's focus on short-term events, Sabrina was concerned with longer-term issues. For example, at the beginning of the school year when Ellie discussed introducing "book clubs" during reading time, Gina immediately proceeded to supply Ellie with actions that she should take to embark on this activity. Then, by contrast, the following exchange took place between Sabrina and Ellie:

\section{Excerpt 2}

S: Remember, your approach to book clubs can morph over the year. You want to be thinking about what you want it to look like in January. What do you see it looking like right now? If you had to go in tomorrow?

E: Chaos.

S: Okay, your eyes just got really big. [Utterance omitted] So what I'm reading from your facial expression is that right now it's not going to happen.

E: I mean it could, but I don't know. I don't even want to think about this yet.

S: So we're not going to.

E: But I really like it.

S: So this may be a January thing and right now maybe it's guided reading with a ten-minute talk about the book.

In this excerpt, Ellie first expressed her unwillingness to think about the book club, either immediately or in the future and Sabrina accepted her position. However, 
Ellie later admitted that, in principle, she liked the idea. Sabrina deftly followed this up with a compromise that accepted Ellie's current attitude but also allowed her to return to the topic in the future.

In general, then, Gina focused on the immediate past and future, using the coaching conference as an opportunity to evaluate recent classes and to plan activities for upcoming ones. Gina's guidance was thus offered within a shorter time frame, e.g. "Is there anything you can do today that will prepare you for tomorrow?" and "What can you do to ensure that the group goes there tomorrow." By contrast, taking a longterm approach to Ellie's development, Sabrina frequently took the opportunity to highlight ideas and attitudes that Ellie had expressed in previous coaching cycles in order to show her how she was progressing.

This evidently made an impression on Ellie, for, in the interview three years later, she recalled, "(Sabrina) always remembered everything. Whatever I said, maybe I don't even remember that I said it, and she would remember and would question me." In the interview, Sabrina stressed the importance of providing teachers with support that led to sustained pedagogical change: "We [People in general] underestimate the value of the interactions within the coaching conversations and their impact in the long term...often we don't think about the long-term feedback that creates a pedagogical shift."

\subsection{Individual versus Group Orientations Toward Students}

The third difference between Gina and Sabrina concerns their ways of thinking about students. When a new issue arose, Gina tended to focus on Ellie's concerns, asking what was more important or feasible for her and emphasizing activity planning and classroom management. With this orientation, Gina tended to treat students as a 
collective group or as unnamed individuals. In their discussions, Gina often referred to the students as a homogenous category, using the pronouns "them" and "they" to refer to the children. Even when she referred to individual students, it was by gender and agerelated categories such as "that girl over there," "the other little kid."

It is important to stress that organizational considerations are certainly important for successful teaching and Sabrina, too, discussed practical pedagogical matters with Ellie. However, she also went beyond them by pushing Ellie to consider the purpose of each activity, not only in relation to her overarching goals but also from the perspectives of her students, seen not only as a group but also as individuals with different interests, cultural and linguistic backgrounds, and developmental trajectories. To this end, Sabrina pushed Ellie to think carefully about the degree to which she was able to take account of individual students' interests and needs and encouraged her to consider how classroom events felt and mattered to the students themselves. Similarly, she encouraged Ellie to create lessons and activities based on students' interests. In adopting these strategies, Sabrina did not downplay Ellie's views and concerns, but rather encouraged her to attend to students' perspectives in order to create optimal conditions for their dialogic engagement with the subject matter.

Furthermore, unlike Gina, Sabrina talked about Ellie's students as unique individuals, often referring to them by name or by their specific attributes. For example, during the last conference, Sabrina suggested that the students themselves might pick topics they found meaningful and, referring specifically to one student by name, Sabrina asked Ellie "Have you asked [him] what he wants to learn?" Sabrina then named two other students, asking Ellie "What are their strengths?" In taking this approach, Sabrina not only showed interest in and knowledge about the students, their names, and their 
individual circumstances, but also modelled a pedagogical approach that takes students' individual perspectives, needs, and their developmental trajectories into consideration.

In all these ways, Sabrina acted as an advocate for the students, often inviting Ellie to do the same. She thus not only encouraged Ellie to discover and take account of her students' perspectives, but also modelled an approach in which each student's individual development was a priority. Further, Sabrina discussed Ellie's learning journey as intertwined with that of her students, invoking an image of Ellie and her students on parallel journeys of development. Significantly, in the interview three years later, Ellie said that, after completing two academic years of Six Standards Instructional Coaching, she continued to enact the practices and principles she had learned. For example, in the video-cued interview, she noted that, in her current teaching when she noticed students' disengagement in particular learning centers (stations), she would have a conversation with the children about these stations and make appropriate changes: "I need to go figure out what wasn't working in our stations. You know after I've talked with the kids and stuff, what is going to work better for us..." It was striking that Ellie used the collective pronoun, we, in relation to teaching and learning, because she had consistently used the dichotomy of I versus they (herself and her students) in the coaching conversations. Referring to Sabrina, she also recalled that coaching was most valuable in:

helping me change the way I see teaching and see kids. And you know the biggest thing honestly is questioning. Questioning the kids more ... then questioning myself, my own teaching. I reflect a lot more than I used to. I remember in the beginning (of coaching) hating it. They wanted us to reflect and I'm like, no I have other things to do. But now I do. I reflect a lot more, you know, what could be better. 


\section{Discussion}

In this section, we discuss how each of the three differences we identified between the two coaches might be explained. We argue that these differences can largely be interpreted as arising from the differences in their underlying values and assumptions about learning and teaching. Further, the different relationship each had with the Six Standards Pedagogy significantly influenced their different conceptualizations of their role as a coach. We are aware of other factors that might have affected the two coaches' discursive choices, including their institutional role, educational backgrounds, and prior experience as a teacher and/or a teacher educator. These factors will be discussed at the end of this section.

With respect to the first difference, reflection versus action, it is reasonable to argue that the kind of coaching that Gina enacted was essentially transmission-oriented, in that, despite the many open-ended questions she posed, the overall goal of her coaching was that of helping Ellie to organize activities effectively for upcoming classes, with the implicit expectation that, as a result, her students would perform satisfactorily in meeting the school district's academic expectations. Gina's approach was what Freire might have characterized as anti-dialogic (1970/2002) or Bakhtin (1986) as monologic. In the interview, Gina averred that she considered her coaching of Ellie to have been effective. She also added that she continued to coach as she had before, but now with more authority, because of her current status as her district's head coach.

By contrast, Sabrina's coaching could be described as intentionally dialogic. She positioned Ellie as an agentive professional who could make informed classroom decisions based on professional judgment. Sabrina encouraged Ellie to develop her own goals for pedagogical activities, and to think further about including activities that she 
had initially rejected as too challenging. Sabrina urged Ellie to question and reflect critically on what had become her routine practices. This questioning can be interpreted as similar to Freire's (1970/2002) problem-posing approach. Acting as a more knowledgeable other, Sabrina modelled reflective questioning in order to provide appropriate assistance to Ellie in her ZPD.

The second difference concerns the ways in which a coach might attempt to help a teacher develop professionally. For Gina, the primary focus was on achieving successful implementations of activities planned for upcoming classes. In contrast to Gina's focus on short-term improvements in the teacher's practice, Sabrina treated the development of a teacher as a trajectory over a longer time-frame, in which a coach provides assistance in relation to the teacher's current goals. While adopting a longer time-frame for teacher development does not guarantee teacher growth, we suggest that it creates more possibilities for development to occur, provided that teachers are willing to re-evaluate their teaching practices.

The third difference - that of their different ways of thinking about the students to be taught - is interlinked with the first two. In her coaching, Gina was oriented towards the needs and concerns expressed by the teacher, while those of students were, at best, a secondary consideration. Because Gina focused on Ellie's role as a classroom manager, she tended to give only secondary attention to the students, referring to them simply as a group or as unnamed individuals. In contrast, Sabrina wanted Ellie to think of her own development as a teacher and also that of each individual student as a continuing learning trajectory. To this end, she urged Ellie to pay close attention to individual students' interests and also their current strengths and difficulties to inform her pedagogical decisions. She also emphasized the uniqueness of each student and her or his individual personal voice. 
Overall, Gina's coaching was primarily concerned with just one level of assistance, that of coach to teacher, which seemed to be largely based on her view of teaching as short-term performance. Sabrina's coaching, in contrast, was concerned with two levels of assistance simultaneously: Coach assisting teacher in her ZPD and teacher assisting students' progress in their ZPDs. Acting consistently across both levels, Sabrina used the way she interacted with Ellie, that is by treating Ellie as an agentive professional, to model the way in which she hoped Ellie would interact with her students. Similarly, by being an active listener to Ellie's ideas and concerns, she hoped that Ellie, in turn, would create space for her students' voices to be heard.

In sum, across the two levels, Sabrina modelled a consistent conception of education, in which teaching takes the form of assisting learning and development by identifying and acting within each learner's ZPD. Furthermore, she emphasized that, for both students and teachers, learning is a continuing trajectory over time.

While previous research on coach-teacher interaction has focused on coaches' stances in moment-by-moment interactions, in the light of the preceding analyses, we suggest that it is not the use of particular linguistic forms or functions that matters the most, but a coach's macro-interactional orientation. This is because it is this macrointeractional orientation to coaching, rooted in coaches' values and assumptions about learning and teaching, that guides their discursive choices in moment-by-moment interaction. By positioning both teacher and students as agents, Sabrina opened up possibilities for the creation of a more equitable and constructive classroom environment.

The divergent interactional patterns that we identified between the two coaches reveal a potential problem inherent in the PD program. As Knight (2007) cautioned, while coaches (or trainers) may be prepared in a particular PD model, their 
appropriation of the model inevitably varies as a result of their existing beliefs about education. Gina, as a district-employed coach, appeared to be constrained to a considerable degree by the pedagogical requirements and expectations for student performance set by her district. By contrast, Sabrina, as an independent coach, was not bound by a school district's requirements; she was able to advocate the kind of pedagogy in which she herself believed. Another possible explanation is that, regardless of their institutional status, each coach's approach was fundamentally shaped by personality, life trajectory, previous education, experience as a teacher educator, and most importantly - by their beliefs about learning and teaching developed prior to becoming a coach. In either case, it is clearly important to take account of coaches' deep-rooted values and assumptions about education, as well as the institutional role and the socio-political milieu in which they work, when attempting to introduce a form of PD that addresses a fundamental shift in pedagogy, as Six Standards Pedagogy does.

Finally, it is worth revisiting Ellie's comments expressed in the interview three years after her involvement in the project. As she recognized, she had internalized Sabrina's why questioning strategy, and found herself reflecting frequently on her practices in the ways in which Sabrina had prompted her to do. However, this development did not occur at the time of the actual coaching; instead it seems to have been a gradual process that occurred over time after the end of her PD.

\section{Conclusion}

The comparison between the two coaches' ways of interacting with Ellie suggests that progressing from being recognized as an exemplary teacher to becoming an effective coach requires further development with respect to the kinds of knowledge, skills, and dispositions that are necessary to become a teacher of teachers. The findings of this study suggest that, from critical sociocultural perspectives on education, an 
effective coach needs to focus simultaneously on the teacher being coached and on the students being taught. What is essential, therefore, is that the coach develop an active understanding of the full range of pedagogical practices that most benefit all types of students, including linguistically and culturally diverse students, in order to relate the curriculum to students' existing knowledge and experiences.

To date, in the relevant literature, the effectiveness of instructional coaching of teachers has tended to be assessed by self-report data and, more recently, by the statistically measured impact of coaching on teachers' classroom practices and on their students' short-term gains in scores on standardized tests. However, we believe that it is necessary to re-assess how effectiveness is conceptualized and measured. Our analysis suggests that sustained development of both teachers and coaches is likely to be a longterm, incremental process, because it involves their critical re-examination of what is involved in teaching and learning. Viewed from critical sociocultural perspectives on education, teaching is conceptualized as assisting students' leaning and engagement in their ZPDs. This necessitates educators making the curriculum content relevant to students, rather than prioritizing the imposed curriculum standards over their interests and/or needs. Seen in this way, it follows that studying a coach's or a teacher's development needs to be treated as a longitudinal project, which includes documenting qualitative changes in her/his thinking and acting over time. Without the inclusion of such qualitative evidence, the findings of quantitative studies cannot be fully understood, much less leveraged, to improve coaching processes more widely.

In this article, as we noted at the beginning, we aimed to generate an "analytic generalization" (Yin, 2003, pp. 31-33) as the basis for the development of a theory of coach-teacher interaction in effective coaching. However, we are not claiming any generalizability based on the findings of our single case study. We also recognize that 
other factors that were not investigated in our inquiry might have contributed to the case-study teacher's learning, both during and after the coaching period. Nonetheless, we do suggest that the observed differences between the two coaches' macrointeractional strategies that are reported in this article could have significant implications for the professional development of coaches, particularly the ways in which they are initially prepared and subsequently supported over time. These concern the relative emphasis that coaches give between the two poles of: reflection or action, long-term or short-term plans for teacher development, and conceptualization of students as individuals or a group. It is also important that coaches modulate this emphasis depending on the developmental trajectories of the teachers being coached.

In order to help coaches become teachers of teachers, we suggest that structured opportunities for reflection should be part of their ongoing professional development. For example, drawing on previous research on video-based professional development (e.g., Barlow, Gaddy, \& Baxter, 2017; Beiseigel, Mitchell, \& Hill, 2018; Mosely Wetzel, et al., 2015), analyses of written or video-cued case studies of coaching can be used as learning activities for novice coaches to examine the values and assumptions about the nature of learning that are embedded in their coaching practice. This requires a shift from novice coaches reflecting on recorded video clips of expert coaches' practices to their sharing and critically analyzing with their peers their own videorecorded coaching sessions, using cycles of praxis (reflection and action) (Freire, 1970/2002). This type of collaborative approach can create a collegial learning environment that may lead to the development of a community of practice that promotes whole school change beyond that in individual classrooms (e.g., Louis, Marks, \& Kruse, 1996; Perez et al., 2007). Furthermore, as Ball and Cohen (1999) argued, such collective work in a supportive environment creates a space for inquiry and reflection, 
allowing coaches to ask questions, take risks, and address problems in their own practice.

Although our analysis was not directly focused on the professional learning and development of coaches, our findings point to the importance of, and need for, further research on this topic, especially research focused on how to develop coaches' longterm growth as teachers of teachers. This is aligned with the call made by scholars, such as Gallucci, DeVoot Van Lare, Yoon, and Boatright (2010) and Gibson (2005), for more empirical studies on this topic. 


\section{References}

Authors. (2017)

Authors. (2014).

Author. (2018).

Bakhtin, M. M. (1986). Speech genres and other late essays (V. McGee, Trans., M. Holquist and C. Emerson, Eds.). Austin, TX: University of Texas.

Ball, D., \& Cohen, D. (1999). Developing practice, developing practitioners. In L.

Darling-Hammond \& G. Sykes (Eds.), Teaching as the learning profession:

Handbook of policy and practice (pp. 3-32). San Francisco: Jossey-Bass.

Barlow, A. T., Gaddy, A. K., \& Baxter, W. A. (2017). Using video as a stimulus to reveal elementary teachers' mathematical knowledge for teaching. Issues in Teacher Education, 26(1), 17-34. doi: 10.1177/0013164407313369

Bean, R. M., Draper, J. A., Hall, V., Vandermolen, J., \& Zigmond, N. (2010). Coaches and coaching in Reading First schools: A reality check. The Elementary School Journal, 111(1), 87-114. doi:10.1086/653471

Beisiegel, M., Mitchell, R., Hill, H. C. (2018). The design of video-based professional development: An exploratory experiment intended to identify effective features. Journal of Teacher Education, 69(1), 69-89._doi:_10.1177/0022487117705096

Bloome, D., Carter, S., Christian, B., Otto, S., \& Shuart-Faris, N. (2005). Discourse analysis and the study of classroom language and literacy events-A Microethnographic approach. Mahwah, NJ: Erlbaum.

Borman, J., \& Feger, S. (2006). Instructional coaching: Key themes from the literature. Providence, RI: Brown Education Alliance. 
Charteris, J., \& Smardon, D. (2014). Dialogic peer coaching as teacher leadership for professional inquiry. International Journal of Mentoring and Coaching in Education, 3(2), 108-124. doi:10.1108/IJMCE-03-2013-0022

Collet, V. S. (2012). The gradual increase of responsibility model: Coaching for teacher change. Literacy Research and Instruction, 51(1), 27-47._doi: $10.1080 / 19388071.2010 .549548$

Costa, A. L., \& Garmston, R. J. with Hayes, C. \& Ellison, J. (2016). Cognitive coaching: Developing self-directed leaders and learners. Lanham, Maryland: Rowman \& Littlefield.

Crasborn, F., Hennissen, P., Brouwer, N., Korthagen, F., \& Bergen, T. (2011). Exploring a two-dimensional model of mentor teacher roles in mentoring dialogues. Teaching and Teacher Education, 27(2), 320-331,doi: 10.1016/j.tate. 2010.08 .014

Creasy, J., \& Paterson, F. (2006). Leading coaching in schools. London, UK: National College for School Leadership.

Deussen, T., Coskie, T., Robinson, L., \& Autio, E. (2007). “Coach” can mean many things: Five categories of literacy coaches in Reading First. Washington, D.C.: U.S. Department of Education.

Dozier, C. (2006). Responsive literacy coaching: Tools for creating and sustaining purposeful change. Portland, ME: Stenhouse.

Freire, P. (1970/2002). Pedagogy of the oppressed. New York, NY: Continuum.

Gadamer, H.G. (1998). Praise of Theory: Speeches and Essays (C. Dawson, Trans.).

\section{New Haven, CT: Yale University.}

Gallucci, C., DeVoot Van Lare, M., Yoon, I., \& Boatright, B. (2010). Instructional coaching: Building theory about the role and organizational support for 
professional learning. American Educational Research Journal, 47(4), 919-

963. doi: $10.3102 / 0002831210371497$

Gibson, S. A. (2005). Developing knowledge of coaching. Issues in Teacher Education, $14(2), 63-74$.

Gutiérrez, K., \& Vossoughi, S. (2010). Lifting off the ground to return anew: Mediated praxis, transformative learning, and social design experiments. Journal of Teacher Education, 61(1-2), 100-117. doi:10.1177/0022487109347877

Heineke, S. F. (2013). Coaching discourse: Supporting teachers' professional learning. The Elementary School Journal, 113(3), 409-433_doi:_10.1086/668767

Hoffman, J. V., Mosely Wetzel, M., Maloch, B., Greeter, E., Taylor, L., DeJulio, S., \& Vlach, S. K. (2015). What can we learn from studying the coaching interactions between cooperating teachers and preservice teachers? A literature review. Teaching and Teacher Education, 52, 99-112._doi: 10.1016/j.tate.2015.09.004

Hunt, C. S. (2016). Getting to the heart of the matter: Discursive negotiations of emotions within literacy coaching interactions. Teaching and Teacher Education, 60, 331-343. doi:10.1016/j.tate.2016.09.004

Hunt, C. S. (2018). Toward dialogic professional learning: Negotiating authoritative Discourses within literacy coaching interaction. Research in the Teaching of English, 52(3), 262-287.

International Literacy Association (2018). Literacy coaching for change: Choices matter. Retrieved from https://literacyworldwide.org/docs/default-source/wherewe-stand/ila-literacy-coaching-for-change-choices-matter.pdf

Ippolito, J. (2010). Three ways that literacy coaches balance responsive and directive relationships with teachers. The Elementary School Journal, 111(1), 164-190. doi: $10.1086 / 653474$ 
Kincheloe, J. L., McLaren, P., \& Steinberg, S. R. (2011). Critical pedagogy and qualitative research: Moving to the bricolage. In N. Denzin \& Y. Lincoln (Eds.), The SAGE handbook of qualitative research (4th ed., pp. 163-177). Thousand Oaks, CA: SAGE.

Knight, J. (2007). Instructional coaching: A partnership approach to improving instruction. Thousand Oaks, CA: Corwin.

Knight, J. (Ed.). (2009). Coaching approaches and perspectives. Thousand Oakes, CA: Corwin Press.

Kraft, M. A., Blazar, D., \& Hogan, D. (2018). The effect of teacher coaching on instruction and achievement: A meta-analysis of the causal evidence. Review of Educational Research, 88(4), 547-588. doi:10.3102/0034654318759268

Lewis, C., Enciso, P., \& Moje, E. B. (2007). Reframing sociocultural research on literacy: Identity, agency, and power. Mahwah, NJ: Lawrence Erlbaum.

Louis, K. S., Marks, H. M., \& Kruse, S. (1996). Professional community in restructuring schools. American Educational Research Journal, 33, 757-798. doi: $10.3102 / 00028312033004757$

Maloch, B., Mosely Wetzel, M., Hoffman, J. V., A. Taylor, L., Pruitt, A., Vlach, S. K., \& Greeter, E. (2015). The appropriation of the Coaching with CARE model with preservice teachers: The role of community. Literacy Research: Theory, Method, and Practice, 64(1), 339-358. doi: 10.1177/2381336915617604

Mercer, N. (2004). Sociocultural discourse analysis: Analysing classroom talk as a social mode of thinking. Journal of Applied Linguistics, 1, 137-168. doi: 10.1558/japl.v1.i2.137

Merriam, S., \& Tisdell, E. (2016). Qualitative research: A guide to design and implementation (4 $4^{\text {th }}$ ed.). San Francisco: Jossey-Boss. 
Mosely Wetzel, M., Maloch, B., Hoffman, J. V., Taylor, L. A., Vlach, S. K., \& Greeter, E. (2015). Developing mentoring practices through video-focused responsive discourse analysis. Literacy Research: Theory, Method, and Practice, 64, 359378. doi: 10.1177/2381336915617611

Murray, S., Ma, X., \& Mazur, J. (2009). Effects of peer coaching on teachers' collaborative interactions and students' mathematics achievement. The Journal of Educational Research, 102(3), 203-212. doi:,10.3200/JOER.102.3.203-212

Neuman, S. B., \& Wright, T. S. (2010). Promoting language and literacy development for early childhood educators: A mixed-methods study of coursework and coaching. The Elementary School Journal, 111(1), 63-86. doi:10.1086/653470

Obara, S. (2010). Mathematics coaching: a new kind of professional development. Teacher Development, 14(2), 241-251. doi_, 10.1080/13664530.2010.494504

Perez, M., Anand, P., Speroni, C., Parrish, T., Esra, P., Socias, M., \& Gubbins, P. (2007). Successful California schools in the context of educational adequacy.

Washington, DC: American Institutes for Research.

Rainville, K. N., \& Jones, S. (2008). Situated identities: Power and positioning in the work of a literacy coach. The Reading Teacher, 61(6), 440-448.

doi: $10.1598 /$ RT.61.6.1

Skinner, E. N., Hagood, M. C., \& Provost, M. C. (2014). Creating a new literacies coaching ethos. Reading \& Writing Quarterly, 30(3), 215-232. doi: $10.1080 / 10573569.2014 .907719$

Tharp, R., Estrada, P., Dalton, S., \& Yamauchi, L. (2000). Teaching transformed: Achieving excellence, fairness, inclusion, and harmony. Boulder, CO: Westview Press.

Tharp, R. G., \& Gallimore, R. (1988). Rousing minds to life: Teaching, learning, and 
schooling in social context. New York: Cambridge University Press.

Toll, C A. (2014). The literacy coach's survival guide: Essential questions and practical answers ( $2^{\text {nd }}$ ed.). Newark, DE: International Reading Association.

Vossoughi, S., \& Gutiérrez, K. (2016). Critical pedagogy and sociocultural theory. In I. Esmonde \& A.N. Booker (Eds.) Power and privilege in the learning sciences: Critical and sociocultural theories of learning (pp. 139-161). New York: Routledge.

Vygotsky, L. S. (1978). Mind in society: Development of higher psychological processes. Cambridge, MA: Harvard University Press.

Walpole, S., \& Blamey, K. L. (2008). Elementary literacy coaches: The reality of dual roles. The Reading Teacher, 62(3), 222-231. doi:10.1598/RT.62.3.4

Wells, G., and Arauz, M.R. (2006). Dialogue in the Classroom. Journal of the Learning Sciences, 15, 379-428. doi: 10.1207/s15327809jla1503 3,

Yin. R. (2003). Case study research (3rd ed.). Thousand Oaks, CA: Sage.

\section{Declaration of interest}

No potential conflict of interest was reported by the authors. 